\author{
SANDIA REPORT \\ SAND2009-4566 \\ Unlimited Release \\ Printed July 2009
}

\title{
Needed Improvements in the Development of Systemic Corrective Actions
}

John A. Campisi

Prepared by

Sandia National Laboratories

Albuquerque, New Mexico 87185 and Livermore, California 94550

Sandia is a multiprogram laboratory operated by Sandia Corporation,

a Lockheed Martin Company, for the United States Department of Energy's

National Nuclear Security Administration under Contract DE-AC04-94AL85000.

Approved for public release; further dissemination unlimited. 
Issued by Sandia National Laboratories, operated for the United States Department of Energy by Sandia Corporation.

NOTICE: This report was prepared as an account of work sponsored by an agency of the United States Government. Neither the United States Government, nor any agency thereof, nor any of their employees, nor any of their contractors, subcontractors, or their employees, make any warranty, express or implied, or assume any legal liability or responsibility for the accuracy, completeness, or usefulness of any information, apparatus, product, or process disclosed, or represent that its use would not infringe privately owned rights. Reference herein to any specific commercial product, process, or service by trade name, trademark, manufacturer, or otherwise, does not necessarily constitute or imply its endorsement, recommendation, or favoring by the United States Government, any agency thereof, or any of their contractors or subcontractors. The views and opinions expressed herein do not necessarily state or reflect those of the United States Government, any agency thereof, or any of their contractors.

Printed in the United States of America. This report has been reproduced directly from the best available copy.

Available to DOE and DOE contractors from

U.S. Department of Energy

Office of Scientific and Technical Information

P.O. Box 62

Oak Ridge, TN 37831

Telephone: $\quad$ (865) 576-8401

Facsimile: (865) 576-5728

E-Mail: reports@adonis.osti.gov

Online ordering: http://www.osti.gov/bridge

Available to the public from

U.S. Department of Commerce

National Technical Information Service

5285 Port Royal Rd.

Springfield, VA 22161

Telephone: $\quad$ (800) 553-6847

Facsimile: (703) 605-6900

E-Mail: $\quad$ orders@ntis.fedworld.gov

Online order: $\quad$ http://www.ntis.gov/help/ordermethods.asp?loc=7-4-0\#online

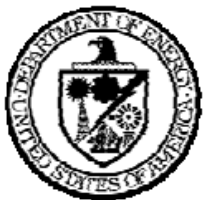


SAND2009-4566

Unlimited Release

Printed July 2009

\title{
Needed Improvements in the Development of Systemic Corrective Actions
}

\author{
John A. Campisi \\ ES\&H, Quality, Safeguards \& Security Audits \\ Sandia National Laboratories \\ P.O. Box 5800 \\ Albuquerque, New Mexico 87185-1030
}

\begin{abstract}
There are indications that corrective actions, as implemented at Sandia National Laboratories are not fully adequate. Review of independent audits spanning multiple years provides evidence of recurring issues within the same or similar operations and programs. Several external audits have directly called into question the ability Sandia's assessment and evaluation processes to prevent recurrence. Examples of repeated findings include lockout/tagout programs, local exhaust ventilation controls and radiological controls. Recurrence clearly shows that there are underlying systemic factors that are not being adequately addressed by corrective actions stemming from causal analyses. Information suggests that improvements in the conduct of causal analyses and, more importantly, in the development of subsequent corrective actions are warranted. Current methodolgies include Management Oversight Risk Tree, developed in the early 1970s and Systemic Factors Analysis. Recommendations for improvements include review of other causal analysis systems, training, improved formality of operations, improved documentation, and a corporate method that uses truly systemic solutions. This report was written some years ago and is being published now to form the foundation for current, follow-on reports being developed. Some outdated material is recognized but is retained for report completeness.
\end{abstract}




\section{ACKNOWLEDGMENTS}

The author would like to extend thanks to Tony Kreuch, clinical psychologist at Sandia National Laboratories. Tony reviewed a draft of this paper and recommended reviewing and adding the Bowen Family model to my discussion of schools of theories of psychology and human cognition. I was influenced by a paper by Jeff Brewer (SAND2005-5730, Risk Perception \& Strategic Decision Making: General Insights, a New Framework, and Specific Application to Electricity Generation Using Nuclear Energy, 2005).

Thanks also for the encouragement received from members of the Advanced Concepts Group with respect to complexity and systems understanding, especially Vice President Gerald Yonas. I had useful discussions on the subjects of systems with co-worker Bill Hossley and systems analyst Phil Campbell. Finally, the author would like to thank Holly Vargo for editorial assistance and Patty Guyer-Stevens for the encouragement to publish. 


\section{PREFACE}

This paper was prepared in 2005 as part of an extensive and detailed study that focused on the causes for recurring issues within the same or similar organizations at Sandia National Laboratories. The paper considered internal and external audit results that cited inadequate selfassessments, corrective actions, and causal analyses. Many of the specifics discussed in this paper are now dated. However, as Sandia continues to improve processes, there remains a need for greater understanding of systems, human behavior, and the impact of complexity for the derivation of more effective corrective actions. Thus, the fundamental concepts expressed in the 2005 paper become even more relevant in 2009. This current relevance prompts the publication of Needed Improvements in the Development of Systemic Corrective Actions.

The author initially struggled to find an appropriate audience at Sandia National Laboratories for these ideas. Should the paper be primarily directed toward those within our institution who were responsible for the corrective action process? Should the paper be directoed toward those who were responsible for developing and revising our management system, or those who led this management system? The author embarked upon a course of discourse with those who could either benefit from the concepts presented herein or who could help improve the underlying bases. Personnel contacted included the management of the Audit Center (the home center of the author), members of the psychology wing of Sandia Medical, members of the Human Factors department, and individuals associated with our Advanced Concepts Group, who were among the most outspoken at Sandia on the subjects of complexity. Unfortunately, all progress made in these areas was hampered by internal transitions in institutional responsibilities, defensive views regarding existing processes, or limited time available from other responsibilities to provide sufficient effort. As an example of internal transitions, the paper was well received by the Advanced Concepts Group (ACG) and its vice president. A collaborative follow-on activity was suggested by the ACG vice president but, before that effort could be realized, the ACG was dissolved and the vice president reassigned. Having followed these fruitless paths, the author decided that this paper should serve as a reference for more focused products with more readily identifiable audiences. However, other pressing work prevented further action to publish.

Over the intervening years, more critical external assessments of the effectiveness of Sandia causal analyses and corrective action process have been received. Currently the leadership for causal analysis resides in the Corporate Governance policy area. One of the decisions made by the management of this policy area was to replace the Sandia developed causal analysis system (Systemic Factors Analysis) with a popular commercial root cause system (Apollo Root Cause Analysis). Although there is no prohibition regarding the use of other methodologies, the Apollo method is corporately supported and formal training in this methodology is included. After receiving initial training in the Apollo methods, the author has seen how this paper could serve as a reference for another paper focused on a well-defined target audience. The target audience for this more focused paper (to be completed in the near future) is Department 12870, since many of its members are now trained in the Apollo method and several of its members are corporately considered highly-qualified analysts. The focus of the paper in development is how to apply systemic and human behavior understanding to arrive at more systemic solutions. ${ }^{\dagger}$

\footnotetext{
${ }^{\dagger}$ It is important to realize that although the Apollo Root Cause Analysis method is very systematic it does not ensure that solutions are systemic.
} 
The realization of the utility of this paper as a reference for other future papers has reinvigorated the author's desire to have this paper published and maintain its accessibility and use as a reference for other, future papers. 


\section{CONTENTS}

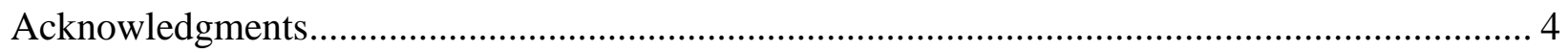

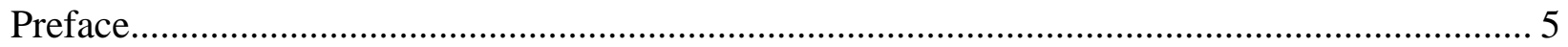

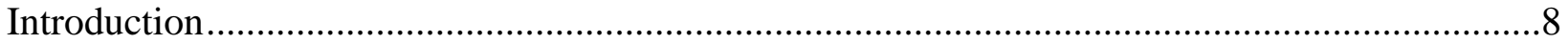

Current State of Causal Analysis and Corrective Actions .............................................................

Need for Improved Causal Analyses and Corrective Actions ..........................................................11

Barriers to Effective Causal Analyses and Development of Meaningful and Effective Corrective

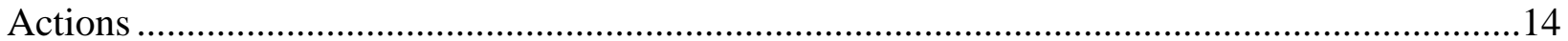

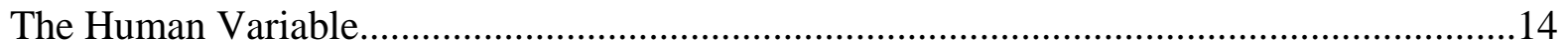

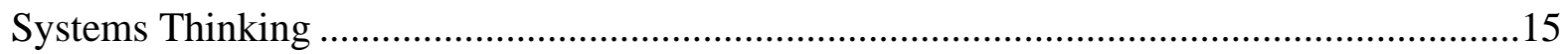

Other Causal Analyses Approaches ....................................................................................20

Accident Investigation ..................................................................................................22

Additional Causal Analysis Techniques...............................................................................21

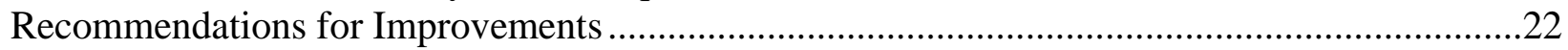

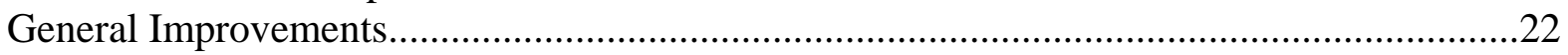

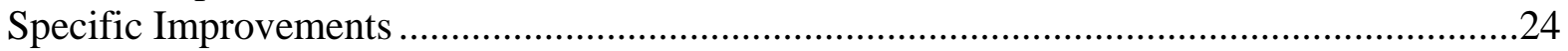

Appendix A Sandia Systemic Factors Analysis Categories ………………………......................26

Appendix B Tier II Causal Analyst Qualification Requirements ......................................................33

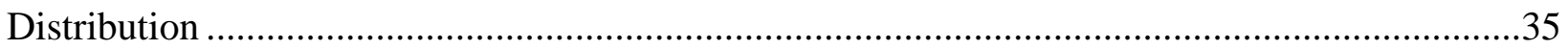




\section{INTRODUCTION}

There is evidence that corrective actions frequently fail to prevent recurrence of the event or condition that they were developed to address. Reviews performed by the author in which causal analyses and systemic solutions were a significant part of the scope and prominent in the results include:

- Special management review of SNL's Price Anderson Amendments Act and Defense Facilities Safety Board Programs (report issued in June, 2005)

- Special management review of the Causal Analyses and Associated Outcomes of Recent Occurrences at the Terminal Ballistics Facility (report issued in November, 2005)

Just prior to issuance of reports documenting the above reviews, the DOE Office of Enforcement issued the draft "Enforcement Guidance Supplement 05-XX: Contractor Investigation, Causal Analysis, and Corrective Actions."1 This guidance indicated that contractor causal analyses were stopping at conditions (such as operator failed to follow procedures) rather than identifying underlying factors.

More generally, there is evidence stemming from review of independent audits (conducted by department 12870), spanning multiple years, of issues recurring within the same or similar operations and programs. ES\&H subjects that have shown repeated findings include lockout/tagout (LOTO) programs, local exhaust ventilation controls and radiological controls. Recurrence clearly shows that there are underlying systemic factors that are not being adequately addressed by corrective actions resulting from the conduct of causal analyses. This information suggests that investigating improvements in the conduct of causal analyses and in the development of subsequent corrective actions are warranted.

\section{CURRENT STATE OF CAUSAL ANALYSIS AND CORRECTIVE ACTIONS}

\section{Causal Analysis and Corrective Actions Guidelines Background}

Formal causal analysis is required whenever there is a reportable occurrence or nuclear safety rule violation. It is also recommended for assessment findings and may be otherwise employed by management as a problem-solving tool. When formal causal analysis is conducted, an SNL qualified analyst is selected to lead a team. The team generally consists of personnel associated with the problem being analyzed, as well as selected subject matter experts. Independence from activities associated with the problem is not required of team members, however it is typical practice that the analyst be independent of the involved organizations and operations. SNL guidance identifies two levels of causal analysis:

\footnotetext{
${ }^{1}$ Subsequent to this report's writing, the DOE document was distributed as a memo and attachment: Stephen M. Sohinki, Dirctor, Office of Price Anderson Enforcement, Enforcement Guidance Supplement 05-01: Contractor Investigation, Causal Analysis, and Corrective Actions, September 23, 2005.
} 
Level I - Root Cause Analyses/Causal Analyses of simple events/findings (i.e., audit findings and self-assessment findings, SSO surveillance findings, etc). It also includes those who will participate on root cause analysis (RCA) teams, but not lead them or serve as an analyst.

Level II - Root Cause Analyses/Causal Analyses, which are performed on more complex events/findings and is required for Occurrence Reports and Nuclear Safety Rule violations.

SNL developed a causal analysis method in the early 1990's based on the Management Oversight Risk Tree (MORT) ${ }^{2}$ method (which was developed to support accident investigations). The SNL causal analysis method is termed Systemic Factors Analysis (SFA). The Sandia approach is generally consistent with DOE guidance for causal analysis (although adjustment is required to translate SNL categories into current DOE causal analysis reporting codes).

Causal analysis is a reduction-based process to identify causes that are labeled as direct, contributing and root. Causes are identified by answering questions arranged in established categories and subcategories. These categories are the result of developing a framework, intended to address the systemic components of the process by which work is accomplished (ideally). In SFA there are seven major categories as follows:

\subsection{MANAGEMENT}

2.0 DESIGN

3.0 EQUIPMENT/MATERIALS

4.0 PROCEDURES

5.0 TRAINING

6.0 OPERATIONS

7.0 EXTERNAL

A complete listing of SFA categories and subcategories is provided in Appendix A.

Guidance and supporting forms for both causal analysis performance and corrective action development is provided through the SNL Internal Restricted Network

(http://www_irn.sandia.gov/esh/om_prgrm/root_cause.htm). A roster of analysts by division, providing individual specific training and tier level classification, is maintained on the web site. Individual analyst classification is determined by completion and submittal of forms by the person intending to perform the function of analyst. The Level II qualification submittal form is more detailed, and qualification is based on total points for specific education, experience, certain professional certifications and specific causal analysis and communication training. If the point total is 12 or greater the individual is qualified as a Level II analyst (see Appendix B). The web site is maintained by a member of department 10312, ES\&H Assurance, Planning \&

\footnotetext{
${ }^{2}$ The MORT system was described by W.G. Johnson in his report MORT - the Management Oversight \& Risk Tree, (SAN 821-2, February 1973) for ERDA. "Tree" refers to the logic diagram that was developed as a graphical index to the MORT document.
} 
Behavioral Based Safety. It should be noted that the subject matter experts, who developed the SFA, are no longer part of the ES\&H organization that owns the process.

The web-based information on our Sandia Restricted Network lists the following common pitfalls for analysts performing causal analyses (Tier I training):

- $\quad$ Placing blame - The purpose of causal analysis is not to assign blame but to identify the issues (i.e., what happened) and how to correct them.

- Faulting the worker rather than the work system - Usually, this is taking the easy way out and indicates that the causal analysis was shallow.

- Quit asking questions too soon - Those who participate in a causal analysis must know the work system under study.

- Being biased, having preconceived notions - Successful causal analysis is based on open and open-minded discussion.

- Being pressured or intimidated - Effective causal analysis comes from honest, open discussions.

These guidelines are necessary for meaningful causal analysis. However, without further amplification of what constitutes adequate knowledge of the work system or the boundaries formed by preconceived notion (bias), it is unlikely that these guidelines are adequate, especially for the occasional practitioner. For the purposes of this paper several guidance statements provided above require additional discussion.

Placing blame/faulting the worker rather than the work system. To obtain meaningful and accurate information, the causal analysis process must avoid the perception of blaming or faulting the worker(s). This is a necessary condition to support open discussion and participation by personnel who had responsibility associated with the outcome in question. However, when human performance is the major contributor avoidance of "blame" becomes difficult. Although rare, if that performance is the result of chosen action that is not in keeping with expectations of an adequately qualified worker, nor encouraged by the "actual system" controlling work, then specific disciplinary action or reassignment may be a justified corrective action. This is an area where nuanced understanding by the analyst of human nature and motivations needed to arrive at a deeper causes and more meaningful corrective actions.

Quit asking questions too soon/having preconceived notions. These concepts are linked in that our tendency to quit asking questions prematurely is frequently due to hitting the boundaries established by our preconceived notions. The most fundamental question should be answered by causal analyses is that of "why." This question is crucially important when dealing with human performance factors, which are at the foundation of all occurrences and management systems. Not all analysts are aware of their own paradigms that they operate within, and which forms the boundaries of their preconceived notions. To be better aware of those built in biases the analyst needs the ability to self-examine and that is a difficult task with high variability among individuals.

Overall the most fundamental limitation, however skillful the analyst may be in leading causal analysis (SFA or similar approaches), the analyst will always be led to causes that are narrowly 
constrained by predefined system sub-categories. These outcomes are useful and necessary, but may be insufficient for the purpose of developing systemic corrective actions that will prevent recurrence. Additional effort is needed in order to develop sufficiently systemic solutions. The composition of the causal analysis and corrective action team is usually at first level management and lower levels. As a result, the span of control of the team is limited. There is no incentive or mechanism for the team to go beyond their span of control when suggesting corrective actions. This is a major stumbling block to systemic solutions.

\section{NEED FOR IMPROVED CAUSAL ANALYSES AND CORRECTIVE ACTIONS}

During fiscal year 2005 two special management reviews were conducted by the Management Advisory Services Team (12801) of the Internal Audit and Advisory Services Center (12800) that strongly suggest improvements in causal analyses are needed. The first of these reviews was the Price Anderson Amendments Act and Defense Nuclear Facilities Safety Board Programs. The following excerpts are from the observations and recommendations from that review:

From the corporate perspective the most significant improvement would result from the PAAA Program taking the lead in developing and applying acceptance criteria for causal analysis to better identify and correct root cause(s) of violations.

One of the key objectives of the PAAA Program is to support Sandia management in performing critical causal analysis and appropriate corrective actions. Based on the reviewer's experience as a member of a review performed two years earlier, which included the root cause aspects of two NTS reports, and a recently released draft Enforcement Guidance ${ }^{2}$ document, there is a concern about the adequacy of root cause analysis at Sandia. This is further supported by the Morgan Lewis Independent Assessment of Sandia National Laboratories’ Price-Anderson Amendments Act Program, June 2003, which identified root cause and corrective actions inadequacies.... Review of the guidance established in Chapter 22 of the ES\&H Manual supports that the depicted formalized approach to causal analysis, although rigorous and useful for binning, does not fully address "underlying factors."

The draft [DOE] Enforcement Guidance provides bases that should be used to guide criteria development. In response to the Morgan Lewis Independent Assessment the PAAA Program pointed to the developing corporate issues management system to address deficiencies in root cause and corrective action. The Corporate Issues Management Process CPR has been issued, but does not provide any guidance that would lead to improved causal analysis.

The referenced draft Enforcement Guidance from the DOE Price Anderson Enforcement Office indicates their concern regarding the state of causal analyses. It is helpful to consider the following excerpts from the OE guidance:

\footnotetext{
${ }^{2}$ See footnote 1.
} 
Based on review of a large number of contractor causal analyses, OE [DOE Office of Enforcement] considers the most significant deficiency to be the tendency for analyses to truncate before getting to underlying issues, i.e., they don't go "deep" enough. In particular, OE has found that contractors frequently conclude the analysis at some failure condition (i.e., failure to follow procedures, inadequate training, inadequate administrative controls) and then identify this condition as the root or underlying cause. Although convenient for binning and trending purposes, these failure conditions often do not represent satisfactory endpoints.

The endpoint of "worker failure to follow procedures" has been frequently cited as an underlying cause in contractor causal analyses, and corrective actions have consequently been focused on retraining or disciplining the worker or revising the procedure or process. Although such actions may be appropriate in some cases, contractors should also evaluate organizational and management issues for any contribution to the failure. A variety of cultural or organizational factors may underlie worker procedural compliance issues, and can include the following:

- Perceived differences in management's actions versus their words

- Local supervisory influences contrary to management's stated expectations

- Emphasis on production or schedule

- Long-standing organizational practices conflicting with procedures and becoming the default process

- Examples set by fellow workers

- Desire for a successful experiment or evolution

A comprehensive investigation of a nuclear safety problem should attempt to identify all the particular influences that are causing the problem, including the management or supervisory influences that affect workers' behaviors. OE recognizes these underlying factors are potentially difficult to identify or "get to" in an investigation, and may require a senior level effort, special expertise, or a number of one-on-one interviews. (Emphasis added.)

The admonition that they “don't go deep enough" should not be taken as asking for more specific causes but for further exploring the underlying motivations that led to the specific failure point. This is an important distinction as it suggests that causal analyses are not adequate when dealing with human behavior and its role in why a certain action did or did not take place. Such underlying motivational factors are frequently controlled by environmental, poorly defined factors such as embodied in reference to organizational "cultural factors.” In the $\mathrm{COSO}^{3}$ approach to assessing management controls these cultural factors are defined as "soft controls." COSO philosophy considers these soft controls to be foundational and fundamental, and that hard controls (things like policy, procedure, command and control systems) cannot fully overcome or compensate for soft control weaknesses. The following things are examples of soft controls:

\footnotetext{
${ }^{3}$ Committee of Sponsoring Organizations of the Treadway Commission, a voluntary private sector organization dedicated to improving the quality of financial reporting.
} 
- Ethics (Integrity, Openness, etc.)

- "Tone at the top" (the existence of clear leadership with actions being consistent with explicitly stated values and goals)

- Competence

- Quality of communications (frequency, accuracy and openness)

- Respect for all employees at all levels

- Shared values

- Quality of teaming between management and staff

- Attitudes

- Morale

As can be seen, soft controls are not precisely definable or easy to quantitatively measure. Many are mainly sensed and judged in a qualitative manner, but they are important to recognize and evaluate in causal analysis and corrective action development.

The second special management review was of causal analyses and associated outcomes for recent occurrences at the Terminal Ballistics Facility. The following excerpts are relevant to this paper:

\begin{abstract}
Although the identified root cause may be less than adequate for the purpose of prevention of recurrence of either occurrence, the total information captured by both RCA [root cause analysis] efforts along with readily obtained supplemental information suggests a more complete and actionable cause.
\end{abstract}

It is noted that corporate guidance for the use of Systemic Factors Analysis is, in the opinion of the reviewers, not sufficient in itself to assure effective RCA....All corrective actions adequately address the causes identified by the process and are meaningful steps to preventing recurrence of similar incidents. However, the review team is of the opinion that the identified actions, in total, are not sufficient to prevent recurrence of similar occurrences.

In addition to these specific reviews, whose scope required review of causal analyses and corrective action, and the documented DOE concern with the state of causal analysis, there is substantial evidence accumulated over years by the Independent Audit and Advisory Services Center that recurrence of similar issues is relatively common. This is particularly true with certain ES\&H programs including:

- Lockout/tagout (LOTO)

- Local exhaust ventilation controls

- Construction safety

- Radiological controls

For example review of the 1997 assessment of local exhaust ventilation performed by 12870 shows little difference in terms of the nature of deficiencies from an assessment performed by 
12870 in 2005 . Such results strongly suggest the need for improved causal analyses and more systemic corrective actions.

\section{BARRIERS TO EFFECTIVE CAUSAL ANALYSES AND DEVELOPMENT OF MEANINGFUL AND EFFECTIVE CORRECTIVE ACTIONS}

\section{The Human Variable}

The behavior of humans whether in action taken or omitted is at the root of all cause and effect that we may analyze. This is true whether the event is caused by natural phenomena or human actions or inactions. We design systems and components to withstand natural phenomena within a certain range of probability. The choices that are made reflect human knowledge and cognitive abilities. So, regardless of the type of initiating event, at the root, where things can be addressed, lies human behavior and normative knowledge.

There are several schools of thought for investigating human behavior. For the purposes of this paper there are two primary approaches 1 ) the inside the person tailored view or 2) the systems model where behaviors are explained from observable responses to observable stimuli. Practitioners frequently treat these views as opposed camps where following one precludes following the other ("either/or" as opposed to an "and" perspective), which is discussed further under Systems Thinking.

Psychological models provide paths that allow more insight into human behavior. A brief summary of some of the better-known schools includes:

- Structuralism and Functionalism (Wilhelm Wundt) - Structuralism focused on explaining conscious experience (particularly feelings and sensations) by breaking it down as a series of components or structures. Introspection is the key tool used in structuralism by training subjects to observe and report their mental processes and associated feelings. Functionalism shares aspects with structuralism but differs most significantly with respect to the relationship between emotions and cognition. Functionalism holds that emotions are the result of cognitive processes leading to bodily reactions, which then lead to the experience of emotional states.

- Behaviorism (John B. Watson, B.F. Skinner) - Behaviorism is a school of thought where internal processes are not the focus in direct contradiction to structuralism. Behaviorists believe that descriptions of inner experience are not reliable nor needed. Behaviorism is the study of the outward behavior to external stimuli. The most extreme behaviorists believe all behavior may be explained as a series of responses to specific stimuli. This leads to the conclusion that all behaviors can be accurately predicted once the stimuli-response relations are known.

- Gestalt (Max Wertheimer) - Gestalt is a school of thought that followed as a reaction to structuralism in a similar way as the development of behaviorism. Its main departure was that perceptions of the external world could not be broken down into structural components. Instead perception of patterns in the external environment as a whole drive our reactions and not specific individual stimuli. It differs from 
behaviorism in that behaviors as well as perceptions should be studied as patterns of response.

- Psychoanalysis (Sigmund Freud, Erik Erikson) - This branch of psychology holds that mental dysfunction stems from repressed feelings buried within our unconscious minds and arise during key developmental stages as the individual grows. Sigmund Freud used several methods to surface these feelings and to help the subject understand, accept and deal with them.

- Cognitive psychology - This branch is based on the belief that there is more to human nature than stimulus-response connections. Psychologists of this school concentrate on such mental processes as thinking, reasoning, and self-awareness. They investigate how a person gathers information about the world, processes the information, and plan responses.

- Humanistic psychology - This school developed as an alternative to behaviorism and psychoanalysis. Humanistic psychologists believe individuals are controlled by their own values and choices and not entirely by the environment, as behaviorists think, or by unconscious drives, as psychoanalysts believe. The goal of humanistic psychology is to help people function effectively and fulfill their own unique potential.

- Bowen family systems theory (Murray Bowen) - Is a system perspective of human behavior that views the family as an emotional unit and uses systems thinking to describe the complex interactions in the unit. It is the nature of a family that its members are intensely connected emotionally. This approach is applied beyond the nuclear family to work relationships and organizational emotional states.

- Social styles or other personality based approach such as Myers-Briggs.

Study of these schools, at least to the level of having general knowledge, should improve the analyst's insight to human behavior.

Understanding human behavior is essential to effective causal analysis. Although understood at the intuitive level, some additional formal training would help improve the capability of the analyst in gaining insight. The SNL goals of mission success and operational excellence, can only achieved by greater incorporation of insights into human behavior and systems thinking (as discussed below) into the overall Sandia approach to solution development and self-governance.

\section{Systems Thinking}

To a substantial degree the success of causal analyses leading to effective corrective action is dependent upon:

- the depth of systemic thinking by the analyst and corrective action developer (including fundamental understanding of human cognitive processes, resulting human behaviors and organizational dynamics); and,

- the degree that the actual "system" controlling the performance of work is defined. 
System thinking requires the ability to deal with the inherent "complexity" of human systems. It is arguable that human thought and resulting behaviors are complex and that systems of individuals are also complex. It is a realm where the guidance to "keep it simple stupid" does not apply. Instead, Einstein's quote of “make everything as simple as possible, but not simpler” is appropriate.

For the sake of this paper the following aspects of complexity are important to note:

- Complexity is the property of a real world system that limits the ability of any one formalism being adequate to capture all its properties.

- Complexity refers to situations where many simple interacting parts produce a collective unexpected behavior referred to as a system emergence. ${ }^{4}$ In fact the essence of a complex system is the existence of a property that is lost as the system is reduced to its parts. 5

- Emergent behaviors, of particular interest to complex systems and the conduct of causal analyses and corrective action, are self-organization and other adaptive qualities of the system.

Typical causal analyses are reduction-based in that high level system components (like SFA categories) are reduced to sub-components and processes in a linear manner. Since such approaches rely on breaking the system down into key manageable components, they have inherent limitations when dealing with complex systems. The interfaces that exist between subcomponents are not always identified nor well defined. Although business paradigms, centered on holistic approaches, have been expressed by various business gurus (e.g., Peter Senge) natural resistance to change and limited ability to deal with complexity has generally led to these being cast as feel good but not useful on the day-to-day operations level. However, if we are to improve systemic understanding, utilization of holistic approaches is necessary. The ability of the analyst to deal with the fuzziness of complexity, and to have both reduction and holistic capabilities, is crucial for both the purpose of causal determination and systemic corrective actions.

Ideally, the response of complex systems to various stimuli and environmental conditions are best captured by the construction of computer-based simulations with appropriate relationships (including feedback) between the individual components or agents. In addition, the relationship with the external environment (system of systems) that system under study resides in is taken into account via specification of initial and boundary conditions. The effort required to develop computer models to attempt to predict outcomes of complex system is likely to be prohibitively costly for all but the most high consequence scenarios. Further development of human agents may result in plug-in sub-routines that could simplify this modeling process.

From a causal analysis perspective and, more generally, a management system perspective, improvements are more likely to result from efforts focused on understanding the dependencies and probabilities that affect how systems work and under what conditions do system elements

\footnotetext{
${ }^{4}$ From http://www.cosin.org/lectures/complexity.htmm, The Cosin Project (Dynamical Networks)

${ }^{5}$ From http://www.people.vcu.edu/ mikuleck/ON\%20COMPLEXITY.html, by Professor D. C. Mikulecky, College of Virginia Commonwealth University
} 
function best. This is especially true for research and development efforts where operations are not well characterized and success is highly reliant upon interdependent processes and work environments that foster creativity. To support this understanding of dependencies of components and probabilities affecting outcomes there is a need for better understanding of the fundamental principles and processes that govern human behavior and group dynamics (see section above). This situation, the need for understanding the underlying principles and processes, is analogous to science-based engineering ${ }^{6}$ and suggests an approach that we could call science-based management.

Significant barriers to understanding complex systems encountered by the author include:

- The tendency to view alternative approaches or systems through a competitive lens as either/or rather than potentially complementary or combinatorial (i.e., dichotomous rather than dialectical).

- Not taking into account the impact of situational or environmental factors for the observed outcome.

- Making black-and-white value-based judgments of individuals.

- Generalizing or projecting one's own behaviors (or distorted view of what one's own behavior would be in a similar situation) on others.

- The tendency to see causes and outcomes as strictly linear (if $\mathrm{z}$ follows y then more $\mathrm{y}$ produces more z) and one-way (no feedback loops).

- Difficulty in seeing causal relationships when cause and effect are separated by significant delay.

These tendencies are the reflection of human nature to simplify complex situations in order to act. However, complex systems and human behavior are not reducible to simple components or responses. Following whatever methodology in a rote fashion is unlikely to lead to detection of underlying causes or effective systemic corrective actions.

Examples of the either/or thinking and lack of analysis of environmental factors are seen in some of Sandia benchmarking activities and the subsequent effort to adopt "lock, stock and barrel" approaches from dissimilar organizations. The need to understand the differences in the business environment and culture of Sandia versus the business entity whose model is being advocated is frequently overlooked. In this situation, the either/or mentality leads to all-ornothing-at-all approach preventing the adoption of selected practices (parts and pieces) that could replace less-than-adequate Sandia practices while not requiring other changes that may prove counterproductive. In a similar vein, making black and white value judgments or applying other limiting views to individuals is not an appropriate starting point for systemic understanding.

Decision-making is a crucial aspect of causal analyses and corrective action development. A SAND report “Risk Perception \& Strategic Decision Making” by Jeffery Brewer ${ }^{7}$ provides

\footnotetext{
${ }^{6}$ Science-based means utilizing the most fundamental principles, rather than only empirical data, to develop models that will more accurately exhibit the behaviors of a real world system.

${ }^{7}$ SAND2005-5730 Risk Perception \& Strategic Decision Making: General Insights, a New Framework, and Specific Application to Electricity Generation Using Nuclear Energy, Jeffery D. Brewer
} 
useful insight to the decision making process. This report also provides a framework to identify the sources and nature of bias. Here are excerpts from the abstract of the SAND report:

This report brings together insights regarding risk perception and decision-making across domains ranging from nuclear power technology safety, cognitive psychology, economics, science education, public policy, and neural science (to name a few). It forms them into a unique, coherent, concise framework, and list of strategies to aid in decision-making. It is suggested that all decision makers, whether ordinary citizens, academics, or political leaders, ought to cultivate their abilities to separate the wheat from the chaff in these types of decision-making instances. The wheat includes proper data sources and helpful human decision making heuristics; these should be sought. The chaff includes 'unhelpful biases' that hinder proper interpretation of available data and lead people unwittingly toward inappropriate decision-making 'strategies'; obviously, these should be avoided...

Furthermore, it is emphasized that one's personal decision making biases can be examined, and tools can be provided allowing better means to generate, evaluate, and select among decision options.

Of particular interest are the biases stemming from individual specific characteristics and from human cognitive processes (referred to by the SAND report author as "knowledge availability"). The perturbation that arises as a result of the conceptual framework and biases that the analyst brings to review system components is analogous to the "observer effect" or "observer bias." 8 This perturbation needs to be minimized and/or taken into account when analyzing or developing systemic corrective actions. In order for the analyst to identify his or her own biases, an honest introspection or self-assessment is necessary (particularly in identifying unchallenged assumptions and core principles). Accurate introspection is a quality that varies significantly from individual to individual.

The works of Jamshid Gharajedaghi address the issues of system understanding and related barriers quite directly. Here are some particularly applicable excerpts ${ }^{9}$ :

\section{3: Systems Theories}

I have argued extensively elsewhere (Jamshid Gharajedaghi 1999) that five systems principles of openness, purposefulness, multidimensionality, emergent property, and counter-intuitiveness, along with five systems dimensions define the essential characteristics and the behavior of a socio-cultural system.

Openness means that the behavior of open (living) systems can be understood only in the context of their environment. Therefore no problems or solutions can be entertained free

\footnotetext{
${ }^{8}$ In social science what is observed can be changed by the act of observing it, and by the attitudes of the observer (from the glossary of "A History of Media” by W. Lambert Gardiner. The related social-science term observer bias is error introduced into measurement when observers overemphasize behavior they expect to find and fail to notice behavior they do not expect (from the Wikipedia at http://en.wikipedia.org/wiki/Observer_effect.

${ }^{9}$ Systems Methodology, A Holistic Language of Interaction And Design

Seeing Through Chaos and Understanding Complexities, February, 2004 Jamshid Gharajedaghi
} 
of context. However, a tendency to define the problem in terms of the solution, and a strong preference for the context-free solution, that is tried and true, keep producing the same non-solution all over again. Open (living) systems exhibit a tendency toward a predefined order. Left alone they reproduce themselves.

Purposefulness. Why people do what they do is the matter of purpose, that of choice. And the choice has rational, emotional, and cultural dimensions. Rational choice is the domain of self-interest, or the interest of the decision maker, not the observer. A rational choice is not necessarily a wise choice. It reflects only the perceived interest of the decision maker at the time. The emotional choice is the domain of beauty and excitement. We do lots of things because they are exciting or, more precisely, because they are challenging. If the excitement of a good challenge were not part of our decision criteria, life would be a bore. In other words, setting and seeking attainable goals is a banal existence.

Culture defines both the cognitive and the normative behavior of the collectivity. Just like a high-level computer language that provides default parameters when the programmer fails to choose one, the culture provides default values when actors fail to choose one explicitly.

Multidimensionality is probably one of the most potent principles of systems thinking. It is the ability to see complementary relations in opposing tendencies. The mutual interdependence of opposing tendencies is characterized by an "and" instead of an "or" relationship. Unfortunately, for the majority of cultures, a fallacy has dominated the treatment of opposing tendencies as a duality in a zero-sum game. Everything seems to come in a pair of opposites: collectivity/individuality; security/freedom; modernity/tradition, order/complexity; art/science and so on. They are cast in such a way that a win for one is invariably associated with a loss for the other. If $\mathrm{X}$ is true then NX cannot be true. This represents an "or" relationship. Multidimensionality states that lose/lose and win/win as well as win/lose are possibilities and it denies the fallacy that if $\mathrm{x}$ is good more $\mathrm{x}$ is even better.

Counter-intuitiveness. Social dynamics stand on a level of complexity beyond the reach of the analytical approach. Counter-intuitiveness means that actions intended to produce a desired outcome may, in fact, generate opposite results. Things can get worse before getting better, or vice versa. One can win or lose for the wrong reason. To appreciate the nature of counter-intuitive behavior, one needs to understand the practical consequences of the following assertions:

- Cause and effect may be separated in time and space.

- Cause and effect can replace one another, displaying circular relations.

- An event may have multiple effects. The order of importance may shift in time.

- An effect may have an independent life of its own. Removing the cause will not necessarily remove the effect.

Emergent Properties are the property of the whole, not the parts, and thus cannot be analyzed; they are the product of interactions among the parts. The mere notion of interaction signifies a dynamic process. In other words, the emergent phenomenon is a 
time-dependent state reproduced continuously online and real time. Therefore, life, love, happiness, and success are not a one-time proposition; they have to be reproduced continuously. If the processes that generate them come to an end, the phenomena cease to exist as well. They cannot be stored or saved for future use.

Understanding and applying the concepts touched upon above to causal analyses and systemic corrective actions are critical for meaningful improvements.

\section{OTHER CAUSAL ANALYSES APPROACHES}

\section{Accident Investigation}

Another process, accident investigation, is mandated when reportable events lead to consequences exceeding DOE defined thresholds. There are key differences between the accident investigation process and root cause analysis that are worth examination. DOE Order 225.1A, Accident Investigations:

- requires that accident investigation be performed by an independent board,

- are not "constrained" by the requirement to assign fixed causal codes,

- shall include analysis of management control and safety systems,

- requires statement/judgment of overall needs as long as supportable by "facts."

A key distinction between causal analyses and accident investigation is that the board is not expected to identify a root cause, but to render "judgment of needs." This judgment allows full consideration of the control systems from any perspective. In addition, it has provisions to capture minority opinions in case the board is not in consensus.

A causal analysis system incorporating some of these less constraining features than in the SFA will be more effective in developing complete and systemic corrective actions especially under specific conditions, such as:

- Whenever involved personnel are in conflict on actions taken or in taking responsibility.

- Whenever there are indications of overt wrong doing with the potential of collusion to prevent discovery.

Under these conditions it is likely that involved personnel, as members of the causal analysis team, would likely confound or withhold evidence.

Adoption of some aspects of the accident investigation techniques could improve causal analysis. Some of these techniques, such as independent teams and minority opinions, are worth considering, particularly in situations listed above. The key most meaningful aspect of accident investigation to consider for adoption is the rendering of an overall judgment of needs. Judgment of needs, not constrained by fixed causal codes, allows for more complete systemic corrective actions. 


\section{Additional Causal Analysis Techniques}

There are several other causal and corrective actions techniques that may be more effective or may have elements that could be incorporated into the SNL causal analysis methodology. Some of the more promising techniques examined by the author include:

- Archetypes for Ogranisational Safety by Karen Marais and Nancy Leveson, MIT, Cambridge, Massachusetts ${ }^{10}$

- Multilinear Events Sequencing-based Investigation Technology (MEST) ${ }^{11}$

- The Why-Because Analysis Method (WBG) $)^{12}$

The following technique descriptions are largely from the authors of the technique:

Archetypes is based on a framework using system dynamics to model the dynamic behavior of organizations in accident analysis. Most current accident analysis techniques are event-based and do not adequately capture the dynamic complexity and non-linear interactions that characterize accidents in complex systems. We propose a set of system archetypes that model common safety culture flaws in organizations, i.e., the dynamic behaviour of organizations that often leads to accidents.

Modern socio-technical systems are becoming more complex and tightly coupled in response to increasing performance and cost requirements. Understanding these systems and analysing or accurately predicting their behaviour is often difficult. We are seeing a growing number of normal, or system, accidents, which are caused by dysfunctional interactions between components, rather than component failures. Such accidents are particularly difficult to predict or analyse. Accident models focusing on direct relationships among component failure events or human errors are unable to capture these accident mechanisms adequately.

The archetype approach relies heavily on establishing feed back loops (causal loops) between key system components and their intended output.

The Multilinear Events Sequencing-based investigation Technology (MEST) is an integrated body of concepts and procedures for investigating and analyzing a wide range of desired and undesired processes before or after they happen. It can best be viewed as a process investigation and analysis technology.

The basic ideas and components resulted initially from efforts to overcome observed deficiencies during the investigation of accidents, explosions, fires and injuries. Continuing refinement during investigation has led to a new investigation paradigm and investigative technology that could help users understand, and improve other processes during which undesired interactions occur. Functionally, this process

\footnotetext{
${ }^{10}$ http://www.systems-thinking.org/rca/p01-marais.pdf

${ }^{11} \mathrm{http} / / /$ www.starlinesw.com/product/Guides/MESGuide00.html\#a2

${ }^{12}$ A Practical guide to the Why Because Analysis Method - Performing a Why Because Analysis, by Thilo PaulStuve, September 21, 2005.
} 
investigation technology has been found applicable for the investigation of risks and development of standard operating procedures, design of facilities safety reviews, hazard analyses, emergency response assessment, and research. The multilinear events sequencing-based investigative technology has led to several investigative breakthroughs.

One of its most significant breakthroughs is its departure from the judicial heritage which dominates traditional investigation perceptions and practices, such as an adversarial environment, and working at negative goals like causes, fault, blame, failures and error/ MES has made possible a collaborative, open non-judgmental and logic-driven investigation environment, seeking understanding and improvement.

WBG Method. A Why-Because Analysis (WBA) ... starts with gathering information about the incident. This information is then used to construct either a List of Facts (facts listed alone) or a Why-Because List. The construction of the Why-Because Graph (WB Graph, WBG) starts with determining the mishap (the "top node"). Then the necessary causal factors (NCF) that finally led to the mishap are determined, using the Why-Because List, until a chosen level of detail is reached. Finally, the quality (correctness and explanatory completeness) of the WBG is assured by detecting and correcting errors. A report can then be written using the WBG. The WBA process is factored here into eight subprocesses, explained using flowchart notation.

The WBG process includes feedback loops but unlike the Safety Archetype process the loops are relevant to the process itself rather than the system being reviewed.

The review above does not address all the causal analysis techniques that are available. However, review of these three suggest that there are components that could be utilized to develop a more comprehensive methodology that would support systems thinking. Subject matter experts in causal analysis techniques should be utilized to carry out a more extensive review with the goal of improving our capabilities.

\section{RECOMMENDATIONS FOR IMPROVEMENTS}

\section{General Improvements}

The causal analysis process leads the analyst down established paths to pinpoint more specific causes of the outcome in question. In a simplified view, analysis could be considered traveling down the upper portion of an hourglass, with the goal of reaching the root cause(s), corresponding with the neck of the hourglass (as illustrated by the following figure). 


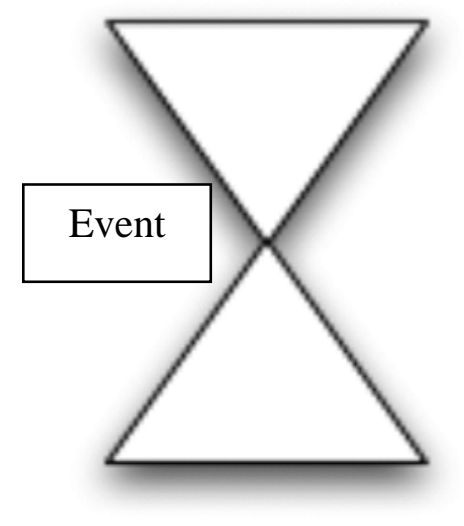

Causal Analysis Approach using SFA
Actual Work System Understood
Cognitive/Behavioral Insight
Causes identified:
- Contributing
- Direct
- Root
Systems Thinking
Judgment of Needs
Component and Component Interactions Understood
Integration of All Causal Information
Meaningful Svstemic Corrective Actions

All the processes in black font, in one form or another, are common to the current causal analyses and corrective action system. In order to arrive at truly effective corrective actions, all the information that results from passing down the hourglass to the neck needs to be integrated by a process that may be envisioned as flowing down the neck of the hourglass to the bottom. Properly developed and integrated system information will lead to systemic solutions that are more comprehensive and more likely to prevent recurrence. This integration process should be unimpeded by predefined system categories, nor by the caveats regarding the appearance of "blame" that would prevent reassignment of personnel or disciplinary actions as potential solutions. The integration process is predicated upon capturing sufficient information on the actual system that accomplishes work. Typically, the actual system is poorly documented and the causal analyst must be astute to capture information that fill in the blanks or corrects the documented system. The suggested additional steps are in red font.

The gathered data uncovered by the causal analysis, depending on the situation and the ability of assigned personnel, may either be integrated by the analyst or passed on to the leader of a separate team to arrive at comprehensive systemic corrective actions. This corrective action team should be led by an individual, independent of the affected organization, whose main qualification should be systemic thinking capability. The analyst should serve as consultant to the team or as a member of the team. This leader should either be at a level with sufficient span of control to effect systemic solutions. Alternatively and more effectively there should be a division between local corrective actions and higher-level systemic actions. The higher-level systemic actions should be sent to a corporate body and mechanism designed to assure that span of control is not a barrier to effecting truly systemic solutions. The Corporate Issues Management system implies by title that it could be the mechanism. However, to date there is little evidence of its functioning as such.

John Stuart Mill offers a definition of causation that supports the need to capture all antecedents rather than focus on a root cause:

It is usually between a consequent and the sum of several antecedents; the concurrence of them all being requisite to 
produce, that is, to be certain of being followed by the consequent. In such cases it is very common to single out only one of the antecedents under the denomination of Cause, calling the others merely conditions.... The real Cause is the whole of these antecedents; and we have, philosophically speaking, no right to give the name of causes to one of them exclusively of the others. ${ }^{13}$

In deciding upon causes and corrective actions, the involved personnel will benefit by identifying, reviewing and clarifying their decision-making process and mental paradigm. Biases should be considered and attempts to limit their influence undertaken.

\section{Specific Improvements}

Detailed improvements regarding causal analysis include:

- Replace the web-based and largely disorganized guidance with a more complete and structured guidance similar to the original Program Guidance (PG) document established in the early 1990's for causal analysis.

- Guidance should include criteria for adopting an independent causal analysis board. Criteria should include:

o Whenever there is lack of consensus among directly involved personnel as to actions taken or omitted.

0 Whenever there are indications of overt wrong doing with the potential of personnel being in collusion to prevent discovery.

- Adopting the "judgment of needs" approach as the final step representing the bridge from causal analyses to systemic solutions.

- Recognizing a higher tier of causal analyst and systemic solution developer that includes training and demonstrated capabilities in:

- Human cognitive abilities and behaviors;

- Dynamics of group behavior;

- Complexity including complex adaptive systems; and

- Systems thinking, including the concept of system of systems.

- Provide a corporate mechanism that allows elevation of systemic solutions to the level of management having adequate span of control to effect.

The last recommendation stems from the recognition that the current process of causal analysis under the guidance of an experienced Tier II analyst is likely to uncover sufficient causes to suggest more systemic solutions. However, the span of control of the team is seldom sufficient to address them. Another corporate mechanism should be established to address these higher level systemic fixes as well as providing the ability to look at multiple incidents over longer spans of time and organization to analyze and integrate to arrive at more effective system solutions.

\footnotetext{
${ }^{13}$ A System of Logic, by John Stuart Mill, first published in 1842 and significantly revised in subsequent editions through 1872.
} 
There are resources at Sandia with expertise in social and cognitive sciences as well as complex adaptive systems and complexity that should be tapped to facilitate improvement in these areas.

A final thought about systems is captured in this excerpt:

The defining characteristic of a system is that it cannot be understood as a function of its isolated components. First, the behavior of the system doesn't depend on what each part is doing but on how each part is interacting with the rest ... Second, to understand a system we need to understand how it fits into the larger system of which it is a part ... Third, and most important, what we call the parts need not be taken as primary. In fact, how we define the parts is fundamentally a matter of perspective and purpose, not intrinsic in the nature of the 'real thing' we are looking at. ${ }^{14}$

${ }^{14}$ Kofman and Senge, Communities of Commitment: The Heart of Learning Organizations' Organization Dynamics, 1993, 22(3), 5-23) 


\section{APPENDIX A. SANDIA SYSTEMIC FACTORS ANALYSIS CATEGORIES}

\subsection{MANAGEMENT}

1.1 REQUIREMENTS: Was the identification and interpretation of requirements adequate?

Identification of requirements

Integration of requirements

Interpretation of requirements

Resolution of conflicting requirements

1.2 PLANNING: Were the overall goals, objectives, and policies adequate?

Management Plan

Established policy

Approved policy

Quality Assurance Plan

Complete policy

1.3 ORGANIZING: Were the organizational structure, resources, functional responsibilities, levels of authority, and interface requirements adequate?

Definition of responsibility or ownership

Job standards

Qualifications of personnel

Number of personnel

Allocation of personnel

Management of change

Facilities

Tools and materials

Integration with other programs

Budget

1.4 DIRECTING: Was the implementation of management plans adequate?

Communication of policy

Scheduling

Records

Tracking of corrective actions

Feedback from implementation

Enforcement of policy

Effectiveness of policy

Cost control

Tracking of goals 
1.5 HAZARD CONTROL: Were the identification, evaluation, and control of hazards and risks adequate?

Hazard identification

Hazard assessment

Safety review

PHC data review

Risk assessment

Administrative controls

Engineered controls

1.6 ASSESSMENT: Was the assessment of operations adequate?

Appraisals/audits

Inspections

Management Surveillances

\subsection{DESIGN}

2.1 SPECIFICATIONS: Was the design specification adequate?

Review

Requirements

Standards

Documentation

Approval

Interpretation of requirements

Interfaces

Life cycle

2.2 PROCUREMENT: Was the process for specifying and buying services, equipment, or material adequate?

General technical specification

Contractual terms

Supplier verification

Unique technical specification

Statement of work

Supplier Quality Assurance

2.3 CONFIGURATION CONTROL: Was the documentation of the as-built configuration of systems or equipment adequate?

Review

Field changes

Accuracy 
Drawings/sketches

Approval

Change implementation

Availability

2.4 HUMAN-MACHINE INTERFACE: Was the equipment used to communicate information from systems to personnel or from personnel to systems adequate?

Labels

Displays

Audible cues

Controls

Layout

$3.0 \mathrm{M}$

3.1 HANDLING: Was the packaging, shipping, receiving, handling, or storage of equipment or materials adequate?

Identification of contents

Receipt inspection

Non-conforming items

Shelf life

Segregation

3.2 MANUFACTURING/CONSTRUCTION/INSTALLATION: Was the manufacturing, construction, installation, or acceptance of equipment or materials adequate?

Standards

Acceptance testing

Application of standards

3.3 MAINTENANCE/TESTING: Was the ongoing maintenance or operability testing of equipment or systems adequate?

Preventive maintenance

Inspection

Calibration

Equipment history

Corrective maintenance

Maintenance and test equipment

Spare parts

3.4 EQUIPMENT/SYSTEM PERFORMANCE: Was the performance of equipment or systems adequate? 
Component failure

Below required performance

Erratic performance

\subsection{PROCEDURES}

4.1 CONTENT: Was the format and content of the written procedure or guidance adequate?

Review

Environmental considerations

Health considerations

Quality control

Specific situation

Sequence

Ambiguity

Presentation of limits

Computations

Equipment identification

Typographical errors Approval

Safety considerations

Emergency considerations

Format

Level of detail

Actions per step

Identification of revised steps

Checklists

Graphics

References

4.2 AVAILABILITY: Was a written procedure or guidance developed and available for use?

No procedure

Out-of-date procedure

Experiment Plan

Test Plan Availability

Operator aids

Standard Operating Procedure (SOP)

Operating Procedure (OP)

4.3 USE: Was a written procedure or guidance used properly?

Followed incorrectly

Did not use

\subsection{TRAINING}


5.1 CERTIFICATION: Was the testing, maintaining qualifications, or documenting qualifications of personnel adequate?

Qualification testing

Records

Continuing training

5.2 DEVELOPMENT: Was the development of training material adequate?

Job/task analysis

Objectives

Program design

5.3 PRESENTATION: Was the presentation of training material adequate?

Classroom

Required reading

Instructor qualifications

On-the-job

Support equipment

Instructor skills

5.4 CONTENT: Was the content of training material adequate?

Systems

Administrative

Safety concerns

Emergency concerns

Facility

Equipment

Environmental concerns

Health concerns

Quality control considerations

5.5 QUALIFICATIONS: Were the education, work experience, or training levels of personnel adequate?

Education

Experience

No training

Physical requirements

\subsection{OPERATIONS}

6.1 DIRECT SUPERVISION: Was the direct control of work adequate? 
No supervision

Preparation

Assignment of worker tasks

Feedback

Excessive supervision

Selection of worker

Briefings

6.2 VERBAL COMMUNICATIONS: Was the verbal presentation or exchange of information adequate?

Method

Timeliness

Between shifts

Understanding

Verification

Communication established

Within working groups

Between shifts and management

Terminology

Length

6.3 CONDITIONS: Were the physical conditions in the work area adequate?

Workplace layout

Climate

Crowded

Radiation hazard

Electrical hazard

Physical barriers

Housekeeping

Lighting

Noise

Chemical hazard

Signs

6.4 CAPABILITIES: Was the physical or emotional ability of personnel adequate?

Overtime

Fatigue

Sensory/perceptual capabilities

Attitude

Inattention

Illness

Motor/physical capabilities

Substance abuse 
6.5 PERFORMANCE: Was the performance of work adequate?

Documentation

Emergency notifications

Verification of actions

Restoration of system

Use of tools

Use of safety equipment

Hazard identification

Inappropriate actions

Quality control

Lockout/Tagout

Use of equipment

Use of protective clothing

Halting unsafe operations

7.0 EXTERNAL

7.1 HUMAN: Was there a human factor beyond the direct control of SNL?

Sabotage

Vandalism

Civil unrest

7.2 NON-HUMAN: Was there a non-human factor beyond the direct control of SNL?

Off-site power failure

Off-site explosion

Hurricane

Flood

Animal interference

Off-site fire

Lightning

Tornado

Earthquake 


\section{APPENDIX B. TIER II CAUSAL ANALYST QUALIFICATION REQUIREMENTS}

\section{SNL Center 10300 Process - Root Cause Analysts Qualification Form (Qualifies Center 10300 Personnel to Perform the Higher Rigor Root Cause Analyses)}

\begin{tabular}{|c|c|c|}
\hline Name & Date & \\
\hline & & Points \\
\hline A. Education (science degrees only) & (4 points Max.) & \\
\hline $\begin{array}{l}\text { Associates degree } \\
\text { Bachelors degree - additional point } \\
\text { Graduate level degree - additional } 1 \text { point } \\
\text { Certified Industrial Hygienist }(\mathrm{CIH}) \text { or Safety }\end{array}$ & sional (CSP) add 1 point & \\
\hline B. Experience & (7 points Max.) & \\
\hline $\begin{array}{l}1 \text { point for each root cause analysis you led } \\
\text { Additional point for each Root Cause you ha } \\
\text { List examples: }\end{array}$ & $\begin{array}{r}\text { (5 points max) } \\
\text { cipated in (2 points max) }\end{array}$ & \\
\hline C. Root Cause Training & (6 points Max.) & \\
\hline $\begin{array}{l}3 \text { points for each root cause-workshop/ train } \\
\text { Workshops/training attended and date(s) tak }\end{array}$ & nded. (6 points Max) & \\
\hline D. Communication/Quality/Personal S & raining $\quad(2$ points Max $)$ & \\
\hline $\begin{array}{l}2 \text { points for having attending a course relate } \\
\text { personal development } \\
\text { Courses and dates taken: }\end{array}$ & etive communication, Quality, or & \\
\hline E. Required Reading & (3 points Max) & \\
\hline $\begin{array}{l}1 \text { point for each document read from the req } \\
\text { the SNL } 6300 \text { Root Cause home page } \\
\text { Documents reviewed: }\end{array}$ & ading list (the list will be kept on & \\
\hline F. Misc. Areas & (2 points Max) & \\
\hline $\begin{array}{l}\text { Background in one or more of the following: } \\
\text { quality, trade or craft, law enforcement, audi } \\
\text { Describe applicable background: }\end{array}$ & $\begin{array}{l}\text { management, problem solving, } \\
\text { essor, Coordinator or Facilitator. }\end{array}$ & \\
\hline Total of Points - & (12 needed) & \\
\hline
\end{tabular}

Signature of Root Cause Analyst 


\section{Instructions for Using the \\ Center 10300 Process - Root Cause Analysts Qualification Form}

\section{Purpose}

This tool provides Center 10300 management and Root Cause Analysts a method to identify the qualifications necessary to be a Root Cause Analyst in Center 10300 for all types of root causes, including the more rigorous root causes associated with complex findings, incidents reportable occurrences, infractions, etc.

This process is patterned after the ASME NQA-1 supplement 2S-3 and App. 2A-3, which is used to determine the requirements for qualification of QA Audit personnel, and is recognized as an industry standard. It serves as corrective action for a finding that there are inconsistent qualification requirements for Root Cause Analysts.

A person is determined to be qualified to serve as a Level II Root Cause Analyst if he or she scores 12 or more points.

It is recommended that a Root Cause Analysts qualifications be revisited every 3 years.

The owning manager is responsible for making sure that a person is well suited to perform a root cause on a case-by-case basis.

You can locate your "historical" training records using the following links From the HR Homepage:

Click on the HR Queries button at the top of the page and drill down to your training (insert your kerberos when requested) HR Queries:

Queries About Me:

My HR Information:

https:/hrprod.sandia.gov/cfdocs/prod/hris/hr/hrq/emp/template/my_emp_info.cfm

Under Education Courses Last Three Years, click on All My Education Courses: 


\section{Distribution}

Lawrence Livermore National Laboratory

Attn: N. Dunipace (1)

P.O. Box 808, MS L-795

Livermore, CA 94551-0808

Gerold Yonas, 00700

Robert Brandhuber, 04110

Doug Bloomquist, 04120

Philip L. Campbell, 05629

Sidney M. Gutierrez, 06700

T.J. Allard, 09750

Alice Maese, 09752

Barbara A. Boyle, 09753

William E. Hossley, 10653

David L. Palmer, 12400

Jennifer Plummer, 12800

Connie Wenk, 12850

Gordon Smith, 12870

John Campisi (5), 12870

$1 \quad$ MS0899 Technical Library

09536 (electronic copy) 


\section{Sandia National Laboratories}

$$
\begin{aligned}
& \text { Diagram } \\
& \text { A6: The } \\
& \text { Building } \\
& 898 \text { and } \\
& 897
\end{aligned}
$$

